\title{
Effective Length Factor of Braced Beam with In-plane buckling in Chevron Braced Steel Frame With Pinned Connections
}

\author{
Yu Haifeng \\ School of Civil Engineering \\ Hebei University of Science and Technology \\ Shijiazhuang 050018, China \\ e-mail:skipperyhf@163.com \\ Zhang Yan \\ School of Civil Engineering \\ Hebei University of Science and Technology \\ Shijiazhuang 050018, China \\ e-mail: flyhighyan@qq.com
}

\author{
Li Qilian \\ School of Civil Engineering \\ Hebei University of Science and Technology \\ Shijiazhuang 050018, China \\ e-mail: 1q16599@163.com \\ Li Jinfeng \\ School of Civil Engineering \\ Hebei University of Science and Technology \\ Shijiazhuang 050018, China \\ e-mail: 1jf198861@qq.com
}

\begin{abstract}
The effective length factor of the braced beam with in-plane buckling in the chevron braced steel frame with pinned connections was derived, and verified in comparison with the value calculated by the eigenvalue buckling analysis using the software ABAQUS. The results show that, the numerical values of effective length factor are basically 0.9-1.1 times of the theoretical values, indicating the numerical and theoretical values agree well with each other. Based on the research conclusions above, the stability design suggestion about the braced beam under frequent and rare earthquakes was put forward.
\end{abstract}

Keywords- concentrically braced steel frame with pinned connections; braced beam; effective length factor; stability calculation; design suggestion

\section{INTRODUCTION}

Under frequent horizontal earthquakes, the expected behavior of chevron braced steel frames with pinned connections is that one side braces are in compression and the other side braces are in tension, resulting in a large axial tension force in one half segment of the brace beam and axial compression force in the other half. It is evident that adopting 1.0 is unsuitable for the effective length factor of the braced beam. Under rare earthquakes, the compression braces are expected to buckle and loose their compressive strength, besides the axial force acted on the braced beams, the unbalanced vertical force is also developed. In order to prevent the undesirable deterioration of braced beams and floors, the Chinese seismic design code GB50011 [1] require the braced beams shall possess the strength to resist this unbalanced vertical force in combination with the gravity loads. Obviously, the axial force acted on the braced beams is not considered by the GB50011 code. For the braced beams with floor slabs, the floor slabs can translate most of the axial force under earthquakes. In order not to overestimate the section of the braced beams, the braced beams are designed according to the designed method of flexural members are suitable. However, for the braced beams without floor slabs [2-4], it may be unsafe if the axial force is not considered in the seismic design. So, the braced beams should be designed according to the design method of compression-bending members, and the study of the effective length factor of the braced beam is necessary. In this paper, the effective length factor of the braced beam was derived, and the numerical validation was also conducted. At last, the stability design suggestion about the braced beam under frequent and rare earthquakes was put forward.

\section{THEORETICAL VALUE OF THE EFFECTIVE LENGTH} FACTOR FOR THE BRACED BEAM WITH IN-PLANE BUCKLING

Under frequent earthquakes, the braces are in the elastic stage and the buckling is not appeared. The braces can provide the brace beams with elastic support action. The calculation diagram is shown in Fig .1 (a). For the upper half segment of the braced beam, the axial tension force is $0.5 \mathrm{P}$. This half segment is a tension-bending member and the buckling problem is not need to be considered. For the lower half segment of the braced beam, the axial compression force is $0.5 \mathrm{P}$. This half segment subject to axial compression force and flexure may be buckling. In this paper, neglecting the favorable elastic support action of the upper segment of the braced beams, the brace supporting point is considered as the inflection point. So, when the stability checking computation of the braced beams under frequent earthquakes is carried out, the axial force and geometrical length were equal to $0.5 \mathrm{P}$ and 0.51 , respectively. 1 is the clear length of the braced beam, which is the distance of the two column faces. Then the effective length factor is 1.0 and the effective length is $1.0 \times 0.51=0.51$. 
Under rare earthquakes, the braces can not provide the brace beams with elastic support action once the braces buckle. Because the compression braces buckle and the tension braces yield, the absolute axial force values in the compression part of the braced beams are not equal to the axial force in the tension part. Considering the limit state, namely the axial force in the compression brace is equal to zero, the force state and deformation curve of the braced beams are shown in Fig .1 (b). The isolated body under a range of 0 0.51, as shown in Fig .1(c), was selected and the coordinate system was also established, then the equilibrium equation [5] was therefore given by:

$$
y^{\prime \prime}+k^{2} y=0
$$

Where $y$ is the deflection in the Y-direction of the braced beam and $k^{2}=\frac{P}{E I}$.

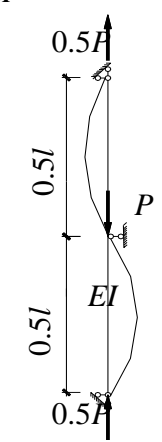

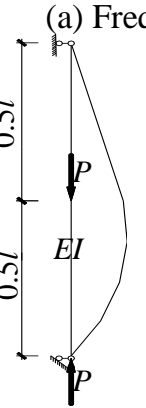

(b) Rare earthquakes

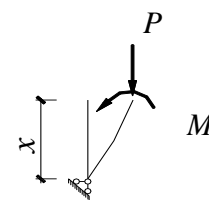

(c) Isolated body
Figure 1. Calculation diagram of braced beam under frequent and rare earthquakes

The general solution of (1) is as follows:

$$
y=A \sin k x+B \cos k x
$$

According to the boundary condition $x=0, y=0$, then $B=0$. (2) can be described as $y=A \sin k x$. When $x$ is equal to $0.5 l$, the deflection and the rotation angle of the upper and lower parts of the braced beam are equal to each other, namely:

$$
\begin{array}{ll}
x=0.5 l & A \sin 0.5 k l=\theta \frac{l}{2} \\
x=0.5 l & A k \cos 0.5 k l=-\theta
\end{array}
$$

Where $\theta$ is the absolute rotation angle of the upper braced beam. Because the rotation angle obtained from the derivation calculus to the $y=A \sin k x$ is a negative value, the right part in (4) has a negative sign. Based on a comprehensive consideration of (3) and (4), the (5) can be obtained.

$$
A(\tan 0.5 k l+0.5 k l)=0
$$

$$
A \neq 0 \text {, then: }
$$

$$
\tan 0.5 k l+0.5 k l=0
$$

Equation (6) is the buckling equation of braced beam, which is a transcendental equation. The critical load $P_{\mathrm{cr}}$ can be obtained through solving (6). Taking the effective length factor of the braced beam as $\mu_{0}$, the critical load $P_{\mathrm{cr}}$ of the braced beam is shown in (7).

$$
P_{\mathrm{cr}}=\frac{\pi^{2} E I}{\left(\mu_{0} l\right)^{2}}
$$

Then:

$$
k^{2}=\frac{P_{\text {cr }}}{E I}=\frac{\pi^{2}}{\left(\mu_{0} l\right)^{2}} \Rightarrow k l=\frac{\pi}{\mu_{0}}
$$

By substituting (8) into (6), the transcendental equation about the effective length factor $\mu_{0}$ can be obtained, as shown in (9).

$$
\tan \frac{0.5 \pi}{\mu_{0}}+\frac{0.5 \pi}{\mu_{0}}=0
$$

By using the (9), the effective length factor $\mu_{0}$ of the braced beam can be calculated. Equation (9) is a transcendental equation, which should be solved through numerical algorithms. Finally, the effective length factor of the braced beam under rare earthquakes is taken as 0.775 . So, when the stability checking computation of the braced beams under rare earthquakes is carried out, the axial force and geometrical length were equal to $P$ and $l$, respectively. The effective length factor is 0.775 and the effective length is $0.775 \times l=0.775 l$.

\section{NUMERICAL VALIDATION OF THE EFFECTIVE LENGTH FACTOR OF THE BRACED BEAM WITH IN-PLANE BUCKLING}

To verify the validity of the theoretical value of the effective length factor of the braced beam, an I-section braced beam numerical model was established using the Abaqus 6.10.1 software ${ }^{[6]}$. As shown in Fig .2, the beam was modeled using the B32 element. The procedure of calculating the effective length factor is as follows: a unit nodal force was applied at the middle point of the braced beam firstly, the first-order eigenvalue was extracted using the eigenvalue buckling analysis. The critical load was the first-order eigenvalue multiplied by the unit nodal forces. Then the effective length factor of the braced beam under rare earthquakes can be obtained through inverse calculation with (8).

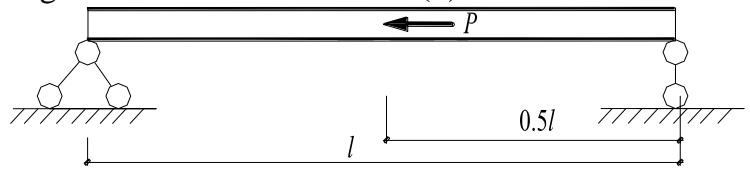

Figure 2. Numerical model of braced beam

Fig . 3 and Table 1 show the comparison between the theoretical and numerical values of the effective length factor of I-section braced beams. The numerical values tends to increase with the increasing of the linear stiffness The reason is may be that the actual buckling deformation curve of the braced beam is not fully consistent with the theoretical curve. However, the effective length factor of the numerical values are basically $0.9-1.1$ times the theoretical values, indicating the numerical and theoretical values agree well with each other generally. Then the conclusion that the effective length factor of the braced 
beam under rare earthquakes is taken as 0.775 was obtained.

TABLE I.

COMPARISON OF THE CALCULATED AND THEORETICAL EFFECTIVE LENGTH FACTOR

\begin{tabular}{|c|c|c|c|c|c|}
\hline \multirow[b]{2}{*}{ number } & \multirow[b]{2}{*}{ I-section(mm) } & \multirow{2}{*}{$\begin{array}{l}\text { Inertia moment } I_{\mathrm{x}} \\
\qquad\left(\mathrm{m}^{4}\right)\end{array}$} & \multirow[b]{2}{*}{ length $(m)$} & \multicolumn{2}{|c|}{ Effective length factor } \\
\hline & & & & numerical & theoretical \\
\hline \multirow[b]{2}{*}{1} & \multirow[b]{2}{*}{ BH300X200X10X10 } & \multirow[b]{2}{*}{0.0001024} & 3 & 0.770 & 0.775 \\
\hline & & & 6 & 0.738 & 0.775 \\
\hline \multirow{3}{*}{2} & \multirow{3}{*}{ BH400X200X10X10 } & \multirow{3}{*}{0.0001979} & 3 & 0.799 & 0.775 \\
\hline & & & & & \\
\hline & & & 6 & 0.745 & 0.775 \\
\hline \multirow{3}{*}{3} & \multirow{3}{*}{ BH500X200X10X10 } & \multirow{3}{*}{0.0003323} & 6 & 0.754 & 0.775 \\
\hline & & & & & \\
\hline & & & 12 & 0.734 & 0.775 \\
\hline \multirow{3}{*}{4} & \multirow{3}{*}{ BH600X200X10X10 } & \multirow{3}{*}{0.0005107} & 8 & 0.748 & 0.775 \\
\hline & & & & & \\
\hline & & & 16 & 0.732 & 0.775 \\
\hline \multirow{3}{*}{5} & \multirow{3}{*}{ HN700X300X13X24 } & \multirow{3}{*}{0.001946} & 10 & 0.749 & 0.775 \\
\hline & & & & & \\
\hline & & & 20 & 0.733 & 0.775 \\
\hline \multirow{3}{*}{6} & \multirow{3}{*}{ BH800X300X20X30 } & \multirow{3}{*}{0.003345} & 10 & 0.754 & 0.775 \\
\hline & & & & & \\
\hline & & & 20 & 0.734 & 0.775 \\
\hline \multirow{3}{*}{7} & \multirow{3}{*}{ BH900X300X20X30 } & & 10 & 0.760 & 0.775 \\
\hline & & 0.004395 & & & \\
\hline & & & 20 & 0.735 & 0.775 \\
\hline & & & 13.3 & 0.753 & 0.775 \\
\hline 8 & BH1000X450X20X40 & 0.009597 & & & \\
\hline & & & 26.6 & 0.734 & 0.775 \\
\hline & & & 13.3 & 0.763 & 0.775 \\
\hline 9 & BH1200X450X20X40 & 0.0145 & & & \\
\hline & & & 26.6 & 0.736 & 0.775 \\
\hline & & & 13.3 & 0.775 & 0.775 \\
\hline 10 & BH1400X450X20X40 & 0.0205 & & & \\
\hline & & & 26.6 & 0.739 & 0.775 \\
\hline & & & 13.3 & 0.788 & 0.775 \\
\hline 11 & BH1600X450X20X40 & 0.0278 & & & \\
\hline & & & 26.6 & 0.742 & 0.775 \\
\hline & & & 13.3 & 0.802 & 0.775 \\
\hline 12 & BH1800X450X20X40 & 0.0364 & & & \\
\hline & & & 26.6 & 0.746 & 0.775 \\
\hline & & & 13.3 & 0.817 & 0.775 \\
\hline 13 & BH2000X450X20X40 & 0.0464 & & & \\
\hline & & & 26.6 & 0.750 & 0.775 \\
\hline & & & 13.3 & 0.834 & 0.775 \\
\hline 14 & BH2200X500X30X60 & 0.0912 & & & \\
\hline & & & 26.6 & 0.754 & 0.775 \\
\hline
\end{tabular}




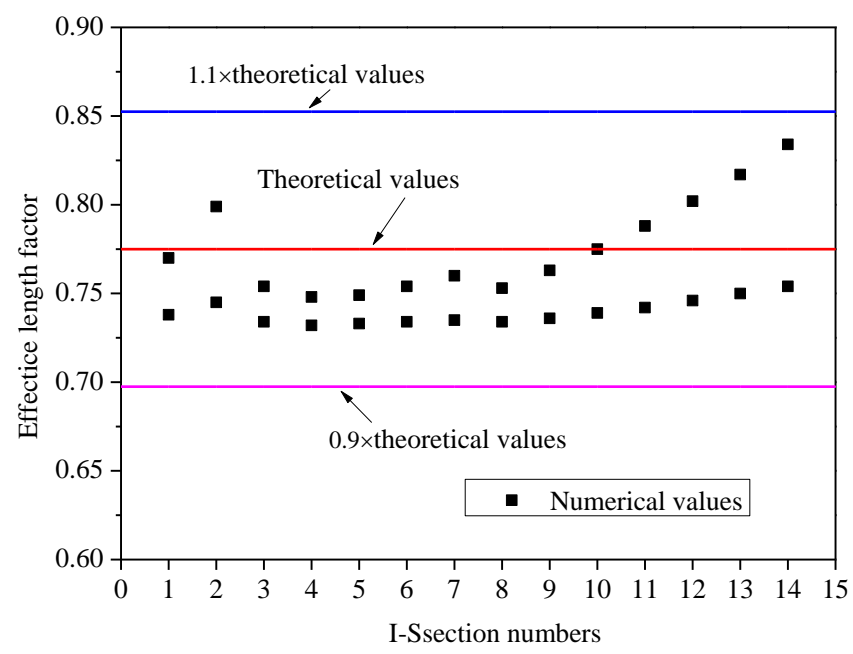

Figure 3. Effective length factor of braced beams

Obviously, the effective length factor will be increase if the elastic support action of the brace is not considered. The stability checking computation of the braced beams was suggested as follows: (1) Under frequent earthquakes, the braces don't buckle, the axial force and moment of the braced beams are calculated using the load combinations provided by the Chinese load code GB50009[7], then the braced beams are checked using the formulae of compression- bending members stipulated by the GB50017 code[8]. Note that the seismic adjusting factor for bearing capacity $\gamma_{\mathrm{RE}}$ should be considered in the braced beam design. (2) Under rare earthquakes, the braces are expected to buckle and loose their compressive strength. To simply design, the axial force in the braced beams are assumed to be equal to the sum of horizontal components of these two forces, which are the yield strength(Afy) of the tension brace and the post-buckling compressive strength( $0.3 \varphi$ Afy) of the compression brace. The moment of the braced beam considered in the design are generated from the representative value of the gravity load and the unbalanced vertical force due to the brace buckling. The braced beams can also be checked using the formulae of compression-bending members stipulated by the GB50017 code [8]. Note that the partial load factors such as 1.3 for the earthquakes force, and the seismic adjusting factor for bearing capacity $\gamma_{\mathrm{RE}}$ should not be considered in the braced beam design, and the design yield stress $f$ of the braced beam steel can adopt the nominal yield stress fy.

\section{CONCLUSIONS}

1) Based on the linear elastic stability theory, the effective length factor of the braced beam with in-plane buckling in the chevron braced steel frame with pinned connections was derived, and verified in comparison with the value calculated using the eigenvalue buckling analysis. In general, the numerical and theoretical values agree well with each other. At last, it is suggested that the effective length of the braced beam under frequent and rare earthquakes are taken as 0.51 and 0.7751 , respectively.

2) The suggestion for the calculation principle of the axial force and moment in the braced beam, and the design procedure of the brace beam under frequent and rare earthquakes has been put forward, which has a guiding significance for the braced beam in the chevron braced steel frame with pinned connections.

\section{ACKNOWLEDGMENT}

This work was financially supported by the National Natural Science Foundation of China (Grant No.51208169), the Natural Science Foundation of Hebei Province (Grant No. E2014208115) and the Five Platform of Open Foundation of of Hebei University of science and technology (Grant No. 2014PT36).

\section{REFERENCES}

[1] GB 50011-2010 Code for seismic design of buildings[S]. Beijing: China Architecture \& Building Press (2010) (in Chinese)

[2] Zhang wenyuan, Yu haifeng, Zhang yaochun, Sun yusong. Design and research on special concentrically braced steel frame with pinned connections [J]. Industrial Construction, 2009, 39(7): 87-91.

[3] Yu HF, Zhang WY, Zhang YC, Sun YS. Shaking Table Test and Numerical Analysis of a 1:12 Scale Model of a Special Concentrically Braced Steel Frame with Pinned Connections [J]. Earthquake Engineering and Engineering Vibration, 2010, 9(1):5163.

[4] Shen zuyan, Huang kuisheng, Chenyiyi,Tongjun. Shaking table test model with steel braced-frame structure about main plant of large thermal power plant [J]. Journal of Architecture and Civil Engineering,2006,23(4):1-5

[5] CHEN Ji. Stability of steel structures theory and design [M], 6th ed. Beijing: Science Press, 2014: 30-40.

[6] ABAQUS, Inc. ABAQUS Scripting User's Manual Version6. 10.1 [M]. Pawtucket, USA: ABAQUS, Inc 2010.

[7] GB 50009-2012 Load code for the design of building structures[S]. Beijing: China Architecture \& Building Press (2012) (in Chinese)

[8] GB 50017-2013 code for design of steel structures[S]. Beijing: China Planning Press (2013) (in Chinese) 